\title{
IMPLEMENTASI PROGRAM DAERAH PEMBERDAYAAN MASYARAKAT (PDPM) DALAM MEWUJUDKAN "KABUPATEN TEGAL OPEN DEFECATION FREE 2019"
}

\author{
YUVA NAELANA, S. BEKTI ISTIYANTO \\ Ilmu Komunikasi, Universitas Jenderal Soedirman \\ Email: naelanayuva@gmail.com \\ Email: bektiis@gmail.com
}

\begin{abstract}
:
The Community Based Total Sanitation Program (STBM) is a program launched by the Ministry of Health of the Republic of Indonesia. One of the pillars of the STBM, Open Defecation Free (ODF), is one of the homeworks of the local government. In contrast to other districts, in Tegal Regency the implementation of this program was regulated directly in the Regent's Regulation on the Regional Program for Community Empowerment. The purpose of this study is to explore further how PDPM will be implemented in an effort to realize Tegal Open Defecation Free District in 2019. The method used in the preparation of this study is descriptive qualitative. The author uses two data sources namely primary and secondary through indepth interviews with three informants and documentation. The results show that so far the Jambanisasi PDPM has been considered successful in building public awareness of the importance of healthy sanitation. The implementation of ODF through the three main components of STBM and triggering techniques to meet the three expectations, namely right target, quality and benefits. PDPM Jambanisasi has succeeded in empowering communities in the health and economic fields through the community of sanitation entrepreneurs.
\end{abstract}

Keywords: Open Defecation Free, STBM, Community Empowerment

\section{PENDAHULUAN}

Kesehatan masih menjadi topik yang menarik di kalangan pemerintah. Soekidjo (2005) menyatakan bahwa kesehatan merupakan hak asasi manusia yang bersifat universal baik sebagai individu, kelompok, masyarakat maupun bangsa. Kesehatan menjadi sumber penting dalam kehidupan manusia, oleh karena itu pemerintah turut bertanggung jawab atas terwujudnya hidup sehat pada masyarakat. Masalah kesehatan yang diakibatkan dari lingkungan tidak sehat masih menjadi masalah besar yang belum terpecahkan. Beberapa masalah kesehatan di sekitar lingkungan kita adalah pembuangan sampah, kebersihan air, dan sanitasi. Masalah tersebut masih menjadi pekerjaan rumah tersendiri bagi pemerintah daerah. 
Memasuki era milenial pun, ternyata masih banyak ditemukan masyarakat yang belum menyadari pentingnya kesehatan lingkungan. Masyarakat desa yang tinggal berdekatan dengan aliran sungai masih enggan untuk memiliki jamban mandiri di rumah. Mereka memilih untuk tetap melakukan perilaku BABS di sungai maupun di pekarangan. Tanpa disadari perilaku tidak sehat tersebut akan berakibat buruk bagi lingkungan. Perilaku BABS juga akan berdampak buruk bagi kesehatan dan menyebabkan berbagai macam penyakit seperti diare, cacingan, dan kolera.

Menurut hasil Riskesdas 2007, diare merupakan penyebab kematian nomor satu pada bayi $(31,4 \%)$ dan pada balita $(25,2 \%)$, sedangkan pada golongan semua umur merupakan penyebab kematian yang ke empat $(13,2 \%)$. Data Kementerian Kesehatan RI hingga tahun 2010 masih ada 45 juta penduduk Indonesia yang masih melakukan BABS. Data tahun 2010 menyatakan sebanyak 162.000 balita meninggal setiap tahun akibat diare, artinya 460 balita meninggal setiap hari. Melihat data tersebut, sebenarnya dari tahun ke tahun telah dilakukan upaya untuk menekan angka penderita diare yang disebabkan perilaku BABS.

Masalah sanitasi bukan hanya perilaku BABS saja, terdapat perilaku masyarakat lainnya yang dapat memicu permasalahan sanitasi. Merujuk pada pengertian sanitasi yang disampaikan Achmadi (2008) bahwa Sanitasi Lingkungan Masyarakat merupakan upaya kesehatan dengan cara memelihara dan melindungi kebersihan lingkungan dari subjeknya. Secara teknis sanitasi dijadikan sebagai usaha yang dilakukan untuk mencegah penularan penyakit melalui penyediaan jamban dan air sehat serta pengelolaan limbah rumah tangga dan sampah.

Upaya yang dilakukan untuk mengurangi penyebaran penyakit diatur oleh Pemerintah dalam Peraturan Menteri Kesehatan No. 3 Tahun 2014 tentang Sanitasi Total Berbasis Masyarakat (STBM). Pengertian STBM menurut Kementerian Kesehatan Republik Indonesia, yaitu:

STBM adalah pendekatan dengan menggunakan metode pemicuan untuk mengubah perilaku masyarakat menuju perilaku yang higienis dan saniter melalui pemberdayaan masyarakat. Pemicuan dilakukan untuk mendorong perubahan perilaku higiene dan sanitasi individu atau masyarakat atas kesadaran sendiri dengan menyentuh perasaan, pola pikir, perilaku, dan kebiasaan individu atau masyarakat menuju perilaku Stop BABS sampai menuju perilaku sanitasi total yakni 5 Pilar STBM (Buku Panduan Pelaksanaan Verifikasi 5 Pilar STBM Kemenkes : 2015.)

STBM dilakukan dengan mengubah perilaku higiene dan sanitasi melalui pemberdayaan masyarakat dengan metode pemicuan. Langkah untuk melakukan penilaian atas kondisi perubahan perilaku yang telah terjadi di masyarakat terkait dengan 5 pilar STBM yaitu : 
1. Stop Buang Air Besar Sembarangan (Stop BABS)

2. Cuci Tangan Pakai Sabun (CTPS)

3. Pengelolaan Air Minum dan Makanan Rumah Tangga (PAMM RT)

4. Pengamanan Sampah Rumah Tangga (PS RT)

5. Pengamanan Limbah Cair Rumah Tangga (PLC RT)

Dengan dikeluarkannya regulasi berupa Permenkes yang langsung mengatur pelaksanaan STBM ini, pemerintah mulai menggalakan beberapa upaya untuk menyukseskan program tersebut. Sebenarnya STBM ini dijadikan sebagai strategi nasional dengan harapan dapat berdampak pada tingkat kesehatan dan kesejahteraan masyarakat. Penyelenggaraan program STBM ini dikerahkan oleh tenaga kesehatan, sanitarian, kader, relawan, masyarakat, dan tentu pemerintah daerah sebagai fasilitator.

Berbagai strategi, program, dan kebijakan dari pemerintah daerah mulai bermunculan untuk menyukseskan program STBM ini. Salah satu yang sering didengar adalah istilah ODF. Beberapa tahun belakangan ini, istilah ODF memang tidak asing lagi didengar. Open Defecation Free atau yang lebih dikenal oleh masyarakat Indonesia sebagai perilaku buang air besar sembarangan (BABS). Open Defecation Free yang selanjutnya disebut ODF merupakan salah satu pilar dari STBM yakni Stop BABS. Pengertian dari Open Defecation Free atau Stop BABS (Stop Buang Air Besar Sembarangan) adalah suatu kondisi ketika setiap individu dalam suatu komunitas, telah berperilaku dan memiliki akses ke jamban sehat dan tidak lagi melakukan praktek buang air besar sembarangan. Kondisi tersebut dapat terwujud dengan teknik pemicuan STBM total.

Sebagai bentuk strategi advokasi dalam pelaksanaan STBM, pemerintah berperan untuk mengeluarkan regulasi agar mendorong penganggaran dan perencanaan program. Salah satu pemerintah daerah yang berkomitmen penuh untuk mewujudkan Kabupaten ODF adalah Pemeritah Daerah Kabupaten Tegal. Komitmen yang telah dibangun melalui regulasi langsung dari Bupati yang diatur dalam Peraturan Bupati Tegal Nomor 2 Tahun 2018 tentang Petunjuk Pelaksanaan Program Daerah Pemberdayaan Masyarakat (PDPM). Tidak hanya itu, PDPM Jambanisasi juga tercantum langsung dalam rencana strategis Dinas Kesehatan Kabupaten Tegal.

STBM dilakukan dengan upaya menumbuhkan kemandirian masyarakat melalui pemicuan dan pemberdayaan masyarakat untuk mewujudkan lingkungan yang bersih dan sehat. Upaya yang dilakukan oleh Pemerintah Kabupaten Tegal untuk mewujudkan pilar pertama STBM ini dilakukan secara bertahap. Di lingkungan pemerintah, program ini lebih dikenal dengan istilah PDPM Jambanisasi. Jambanisasi di Kabupaten Tegal telah dilaksanakan sejak tahun 2017 dan ditargetkan selesai 100\% pada tahun 2019 sebagai Program Daerah Pemberdayaan Masyarakat. 
Program jambanisasi ini tepat dijadikan salah satu program pemberdayaan, karena dilaksanakan dengan upaya meningkatkan pengetahuan dan sikap yang dapat merubah perilaku masyarakat. Pernyataan tersebut didukung oleh Undangundang pasal 1 butir 12 yang menyebutkan bahwa "Pemberdayaan masyarakat desa dilaksanakan melalui upaya pengembangan kemandirian dan kesejahteraan masyarakat dengan meningkatkan pengetahuan, sikap, keterampilan, perilaku, kemampuan, kesadaran, serta memanfaatkan sumber daya melalui penetapan kebijakan, program, kegiatan, dan pendampingan yang sesuai dengan esensi masalah dan prioritas kebutuhan masyarakat desa."

Pemerintah Kabupaten Tegal melalui Dinas Kesehatan Kabupaten Tegal telah menjalankan program ini dengan baik. Diawali dengan komunikasi langsung dengan masyarakat desa yang kemudian ditindaklanjuti dengan pemicuan. Unsur komunikasi yang intensif dan efektif dari pihak yang berperan penting akan berpengaruh langsung terhadap kesuksesan program ini. Disini lah peran serta pemerintah penting dilakukan untuk menciptakan hubungan yang harmonis dengan masyarakat. Hubungan yang harmonis akan membawa kesadaran masyarakat untuk bekerjasama dengan pemerintah mendukung program terwujudnya Kabupaten Tegal ODF 2019.

Hal-hal di atas menggugah ketertarikan penulis untuk mengeksplor lebih jauh bagaimana implementasi PDPM dalam mewujudkan Kabupaten Tegal ODF Tahun 2019. Inilah yang menjadi urgensi pada penelitan ini karena akan mengungkap upaya apa saja yang dilakukan Pemerintah Daerah Kabupaten Tegal dalam pelaksanaan PDPM jambanisasi agar Kabupaten Tegal 100\% ODF pada tahun 2019.

\section{TINJAUAN TEORITIS}

\section{Komunikasi Pemberdayaan Masyarakat}

Mengutip pernyataan Payne (1997) tentang pemberdayaan atau empowerment yang pada hakekatnya bertujuan untuk membantu klien mendapatkan kekuatan (daya) untuk mengambil keputusan dan tindakan yang akan dilakukan dan berhubungan dengan diri klien tersebut, termasuk mengurangi kendala pribadi dan sosial dalam melakukan tindakan.

Pemberdayaan menunjukkan adanya keberpihakan serta kepedulian untuk mengurangi keterbelakangan pada masyarakat dengan menciptakansemangat bekerja sehingga mereka berdaya. Pemberdayaan(empowerment) sendiri menurut konseptual berasal dari kata power, yaitu kekuasaanatau kekuatan. Meminjam istilah Ife (1995), bahwa pemberdayaan atau empowerment secara sederhana dapat dinyatakan sebagai "to increase the power of the disadvantaged" artinya adalah untuk meningkatkan kekuatan atau kemampuan dari yang tidak beruntung.

Pemberdayaan ini wujud upaya untuk memberikan kekuatan, meningkatkan kemampuan dan potensi yang dimiliki oleh individu maupun 
kelompok yang lemah (miskin) hingga menyadari potensi yang dimiliki dan berupaya untuk meninggalkan keadaan keterbelakangan sebelumnya. Penerapan pemberdayaan masyarakat oleh pemerintah dilaksanakan pada beberapa bidang seperti ekonomi, kesehatan, pendidikan dan sosial budaya. Sebenarnya pemberdayaan sendiri merupakan cara pandang baru pada komunikasi pembangunan.

Proses pemberdayaan dapat diwujudkan bila adanya partisipasi masyarakat dalam proses-proses pembangunan yang dilakukan oleh pemerintah (Widjajanti : 2011). Semangat partisipasi masyarakat sangat dikedepankan. Untuk menarik ketersediaan masyarakat dalam berpartisipasi tentu ada langkah komunikasi yang harus dilakukan terlebih dahulu. Oleh sebab itu, sebenarnya pemberdayaan merupakan konsep dari komunikasi pembangunan. Pengertian dari komunikasi pemberdayaan masyarakat yakni proses penyampaian pesan yang terjadi dalam proses atau pun kegiatan pembangunan yang pendekatannya menggunakan pemberdayaan masyarakat.

Merujuk pada pengertian yang disampaikan oleh Ginanjar Kartasasmita (Indarji: 2010) terlihat bahwa komunikasi pemberdayaan masyarakat merupakan kajian yang lebih fokus dari komunikasi pembangunan. Komunikasi pemberdayaan masyarakat merupakan kajian komunikasi dalam kegiatan pembangunan yang menekankan pada pentingnya pelibatan masyarakat atau partisipasi masyarakat. Sehingga proses-proses komunikasi dalam pemberdayaan masyarakat lebih menekankan pada proses yang bersifat transaksionl dan interaktif dari pada linear.

\section{Sanitasi Total Berbasis Masyarakat}

Sanitasi Total Berbasis Masyarakat merupakan adopsi dari keberhasilan pembangunan sanitasi total dengan menerapkan model CLTS (Community-Led Total Sanitation). Dalam upaya menanggulangi masalah sanitasi dan perilaku buang air besar sembarangan, pemerintah melaksanakan program yang diberi nama CLTS. Program CLTS kemudian berganti nama menjadi Sanitasi Total Berbasis Masyarakat (STBM).

STBM adalah pendekatan dengan menggunakan metode pemicuan untuk mengubah perilaku masyarakat menuju perilaku yang higienis dan saniter melalui pemberdayaan masyarakat. Pemicuan dilakukan untuk mendorong perubahan perilaku higiene dan sanitasi individu atau masyarakat atas kesadaran sendiri dengan menyentuh perasaan, pola pikir, perilaku, dan kebiasaan individu atau masyarakat. Penilaian atas kondisi perubahan perilaku yang telah terjadi di masyarakat diukur dengan 5 pilar STBM yaitu :

1. Stop BABS

2. Cuci Tangan Pakai Sabun (CTPS) 
3. Pengelolaan Air Minum dan Makanan Rumah Tangga (PAMM RT)

4. Pengamanan Sampah Rumah Tangga (PS RT)

5. Pengamanan Limbah Cair Rumah Tangga (PLC RT)

Kunci dalam pelaksanaan STBM ini adalah metode pemicuan yang diberikan langsung oleh kader atau fasilitator kepada masyarakat. STBM dilaksanakan melalui pemberdayaan masyarakat dimana masyarakat sadar, mau dan mampu untuk melaksanakan sanitasi total yang timbul dari dirinya sendiri, bukan melalui paksaan. Melalui cara ini diharapkan perubahan perilaku tidak terjadi pada saat pelaksanaan program melainkan berlangsung seterusnya (Depkes RI: 2008). Terjadi untuk memudahkan para kader atau fasilitator merancang strategi pemicuan, terdapat tiga komponen penting dalam pelaksanaan STBM. Pelaksanaan program STBM ini berfokus pada tiga komponen yang saling mendukung yaitu :

1. Enabling environmentyakni menciptakan lingkungan yang kondusif melalui kebijakan, anggaran dan sumber daya serta monitoring dan evaluasi

2. Demand yakni peningkatan kebutuhan sanitasi di masyarakat

3. Supply yakni pemenuhan kebutuhan dan penyediaan akan produkproduk sanitasi yang terjangkau

\section{TUJUAN PENELITIAN}

Penelitian ini bertujuan agar dapat mengeksplorasi upaya yang dilakukan dalam implementasi program PDPM dalam mewujudkan Kabupaten Tegal Open Defecation Free 2019.

\section{METODEPENELITIAN}

Penelitian ini disusun dengan metode deskriptif kualitatif dengan tujuan agar penulis dapat mengekplorasi lebih jauh implementasi Program Daerah Pemberdayaan Masyarakat (PDPM) dalam mewujudkan Kabupaten Tegal Open Defecation Free tahun 2019. Merujuk pada pendapat Moleong (2004) bahwa metode kualitatif sebagai prosedur penelitian yang menghasilkan data deskriptif berupa kata-kata atau lisan dari orang-orang dan perilaku yang dapat diamati.

Pengertian lain penelitian kualitatif menurut Mulyana (2018) adalah penelitian yang bersifat interpretif (menggunakan penafsiran) yang melibatkan banyak metode, dalam menelaah masalah penelitiannya. Penggunaan berbagai metode ini sering disebut triangulasi yang dimaksudkan agar peneliti memperoleh pemahaman yang komprehensif (holistic) mengenai fenomena yang ia teliti. Jadi penelitian ini berupaya menjelaskan dengan menjawab inti permasalahan dengan mencari unsur penting. Sumber data diperoleh langsung dari Dinas Kesehatan Kabupaten Tegal serta Dinas Pemberdayaan Masyarakat dan Desa Kabupaten 
Tegal. Merujuk pendapat Moleong (2006) menyatakan bahwa penetapan fokus yang jelas dan mantap, seorang peneliti dapat membuat keputusan yang tepat tentang data mana yang dikumpulkan dan mana yang tidak perlu dijamah maupun mana yang akan dibuang.

Dalam penelitian ini terdapat dua jenis data yakni data primer dan sekunder. Menurut Kriyantono (2012) data primer merupakan data yang diperoleh dari sumber data pertama di lapangan. Teknik yang digunakan penulis untuk memperoleh data primer yakni wawancara mendalam (indepth interview) bersama 3 informan. Ketiga informan yang dipilih berdasarkan purposive sampling. Menurut Kriyantono (2006) teknik purposive sampling mencakup orang-orang yang diseleksi atas dasar kriteria tertentu berdasarkan tujuan penelitian. Data sekunder diperoleh melalui media perantara seperti bukti, catatan, atau laporan dalam bentuk arsip atau dokumen (Sugiyono: 2013). Adapun data sekunder penulis peroleh dengan teknik telaah dokumen/dokumen tertulis. Data yang dimaksud dapat berupa undang-undang, peraturan, foto dokumentasi program, hasil studi/riset, pernyataan, teori yang relevan, laporan serta bahan lain yang berkaitan dengan program ini. Adapun cara untuk mengetahui keabsahan data tersebut adalah dengan menguji hasil yang telah didapat dengan menggunakan triangulasi sumber.

\section{HASIL DAN PEMBAHASAN}

Pemerintah akhir-akhir ini mengarahkan perhatiannya terhadap kesehatan masyarakat. Kebijakan-kebijakan yang dirancang oleh pemerintah akan berdampak langsung pada kehidupan masyarakat. Saat ini pemerintah kerap mengeluarkan kebijakan yang pro terhadap masyarakat miskin. Termasuk diantaranya Kementerian Kesehatan Republik Indonesia. Seperti yang kita tahu bahwa kemiskinan dan kesehatan merupakan permasalahan yang belum kunjung terpecahkan di negeri ini. Kedua masalah tersebut bukan hanya menjadi masalah bagi pemerintah saja, namun menjadi masalah kita bersama.

Penyebaran penyakit karena lingkungan tidak sehat menjadi permasalahan di tengah masyarakat. Salah satu penyebabnya adalah perilaku BABS. Untuk mengantisipasi peningkatan penyebaran penyakit, pada tahun 2010 terbentuk Community Led Total Sanitation Project atau disebut Proyek CLTS. Seperti yang disampaikan oleh Bapak Nuryadi dalam wawancara :

"Pemicuan itu menjadi bagian yang paling teknis dalam STBM, nama sebenarnya dulu adalah CLTS atau Community Led Total Sanitation yang kemudian masyarakat sederhanakan dalam Bahasa Indonesia dengan sebutan pemicuan yang ada pada STBM. Nah CLTS atau STBM ini adalah salah satu upaya menyadarkan masyarakat agar masyarakat tahu dan faham secara mandiri untuk hidup dengan lingkungan yang sehat." 
CLTS merupakan sanitasi total atas prakarsa masyarakat dengan menitikberatkan pada penyadaran masyarakat akan pentingnya sarana pembuangan untuk kesehatan pribadi serta lingkungan. CLTS kemudian mengalami perubahan nama sejak disahkannya Peraturan Menteri Kesehatan No. 3 Tahun 2014 tentang Sanitasi Total Berbasis Masyarakat (STBM). Pengertian STBM menurut Kementerian Kesehatan Republik Indonesia, yaitu pendekatan dengan menggunakan metode pemicuan untuk mengubah perilaku masyarakat menuju perilaku yang higienis dan saniter melalui pemberdayaan masyarakat.

Program STBM dilaksanakan dengan metode pemberdayaan yakni pemicuan. Sama halnya dengan program pemberdayaan lainnya, implementasi program ini juga bersifat partisipatif. Pemerintah sebagai fasilitator dan pelaksana program berupaya mengajak masyarakat berpartisipasi secara sadar untuk meningkatkan askes sanitasi. Oleh karena itu, Pemerintah kabupaten maupun kota mulai merancang berbagai program dan kebijakan yang berkaitan dengan peningkatan kebutuhan sanitasi. Salah satunya adalah Pemerintah Daerah Kabupaten Tegal. Seperti yang diungkapkan oleh Bapak Thaufiq :

"Program jambanisasi itu kan dilaksankan melalui PDPM kalau start-nya kita dari tahun 2015. Kemudian tahun 2017 Pemerintah Kabupaten Tegal periode Pak Enthus dan Bu Umi mencanangkan program PDPM untuk pembangunan jamban bagi masyarakat miskin karena sesuai dengan basis data terpadu itu ada sekitar $47.642 \mathrm{kk}$ miskin yang belum mempunyai jamban. Kita punya target di tahun 2019 itu Kabupaten Tegal bebas buang air besar sembarangan atau ODF."

Menuju Kabupaten Tegal ODF 2019, Pemerintah Kabupaten Tegal menerapkan pelaksanaan program STBM yang berfokus pada tiga komponen yang saling mendukung yaitu :

1. Enabling environmentyakni menciptakan lingkungan kondusif melalui kebijakan, anggaran dan sumber daya serta monitoring dan evaluasi

2. Demand yakni peningkatan kebutuhan sanitasi di masyarakat

3. Supply yakni pemenuhan kebutuhan dan penyediaan akan produk-produk sanitasi yang terjangkau

Komponen-komponen STBM tersebut juga dijadikan sebagai strategi implementasi Program Daerah Pemberdayaan Masyarakat guna mewujudkan Kabupaten tegal ODF pada tahun 2019. Berikut adalah penjelasan implementasi 3 komponen utama STBM yang diterapkan dalam PDPM guna mewujudkan Kabupaten Tegal ODF 2019.

\section{Enabling Environment}

Pada masa kepemimpinan Bapak Enthus dan Ibu Umi tepatnya mulai tahun 2017, Kabupaten Tegal berkomitmen untuk menekan kenaikan angka 
penyakit akibat lingkungan tidak sehat dengan program jambanisasi. Komitmen tersebut ditunjukkan dengan Instruksi Bupati Tegal No. 440/2500 Tahun 2014 dan Perbup No 2 Tahun 2018 Tentang Juklak PDPM. Program Daerah Pemberdayaan Masyarakat (PDPM) adalah program peningkatan kapasitas pemerintah desa dan pemberdayaan masyarakat yang bertujuan untuk percepatan penanggulangan kemiskinan. Seperti yang disampaikan oleh Bapak Dessy selaku Kabid Aset Pemerintahan Desa, sbb:

"PDPM ini kami persembahkan untuk masyarakat. Sesuai dengan Perbup juklak pelaksanaan PDPM, program ini tujuannya untuk mendorong percepatan pembangunan dan penanggulangan kemiskinan di desa-desa yang ada di Kabupaten Tegal, untuk mewujudkan kebutuhan dasar masyarakat demi mencapai standar hidup dan penghidupan yang layak dan produktif menanggulangi kemiskinan dan meningkatkan derajat kesehatan masyarakat"

Hasil akhir dari implementasi PDPM Jambanisasi adalah terbangunnya jamban sehat di rumah masyarakat miskin yang tercantum dalam PBDT. Bantuan tersebut tidak hanya membangun jamban baru, termasuk juga memperbaiki jamban yang rusak maupun jamban tidak aktif. Melalui PDPM ini, pemerintah memfasilitasi masyarakat miskin untuk belajar menerapkan program STBM dimulai dari pilar pertama.

Pelaksanaan program jambanisasi tersebut diatur langsung dalam Program Daerah Pemberdayaan Masyarakat (PDPM) pada Perbup Nomor 2 Tahun 2018 Tentang Petunjuk Pelaksanaan PDPM. Dikeluarkannya Perbup sebagai naungan hukum yang kuat dalam pelaksanaan STBM, tidak terlepas dari PERMENKES Nomor 3 Tahun 2014 tentang Sanitasi Total Berbasis Masyarakat. Perlu ditekankan bahwa jamban yang baik adalah jamban sehat sesuai dengan definisi operasioanal Kemenkes yaitu terdiri dari kloset, septictank dan resapan.

Perbup tersebut juga berfungsi sebagai penetapan sasaran program dan penerima manfaat. Penerima manfaat jambanisasi berasal dari masyarakat miskin yang telah terdaftar pada Pemutakhiran Basic Data Terpadu (PBDT) Kabupaten Tegal tahun 2015 yang dapat diakses di aplikasi simas.kabtegal.go.id Bappeda dan Litbang Kabupaten Tegal. Perbup ini juga menjadi payung hukum dalam pembentukan dasar anggaran pelaksanaan program. Pembangunan Jamban sehat serentak dilaksanakan setelah dana masuk ke rekening desa, untuk kemudian dikelola dan ditindaklanjuti oleh Timlak di desa dengan mengacu pada RAB dan DED yang sudah di tetapkan di Peraturan Bupati Tentang Petunjuk Pelaksanaan PDPM.

Pemerintah Kabupaten Tegal menggelontorkan anggaran sebesar Rp. 21,75 miliar yang difokuskan untuk penataan dan penyehatan lingkungan, 
khususnya peningkatan akses sanitasi dengan pembuatan jamban sehat bagi masyarakat miskin. Program ini berlaku di 281 desa se- Kabupaten Tegal dengan alokasi proporsional, memperhatikan jumlah penduduk miskin yang tidak memiliki jamban sesuai dengan data Pemutakhiran Basic Data Terpadu (PBDT) tahun 2015.

Berdasarkan data PBDT, saat ini di wilayah Kabupaten Tegal masih ada 47.642 rumah tangga miskin yang masih belum memiliki akses jamban sehat. Pemerintah Kabupaten Tegal berkomitmen untuk tetap mengalokasikan dana PDPM untuk program jamban sehat dari tahun 2017 - 2019 dengan total anggaran sekitar 65,25 milyar untuk dapat membangun 30.330 jamban sehat baru. Hasilnya cukup signifikan, dengan gerakan program ini Pemerintah Kabupaten Tegal berhasil memperbaiki rangkingnya di Provinsi Jawa Tengah, sebagai berikut :

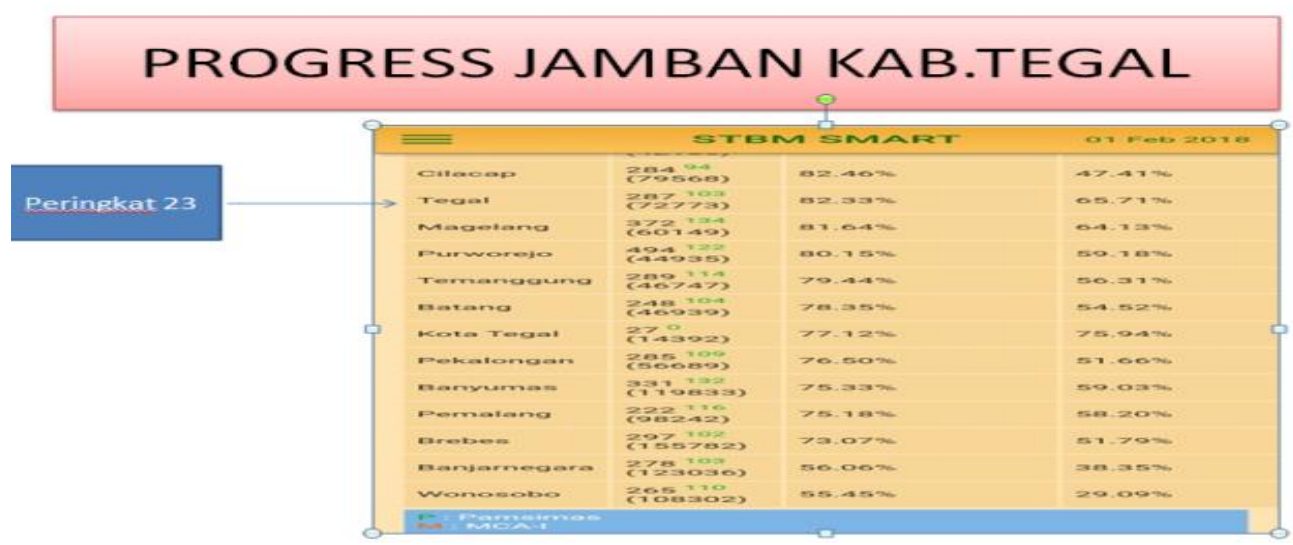

Tabel 1. Progres Akses Jamban Sehat Kabupaten Tegal di Peringkat 23

Sampai saat ini akses jamban sehat Kabupaten Tegal mencapai 83,51\% atau urutan 23 dari 35 Kabupaten/ Kota di Provinsi Jawa Tengah dan diharapkan bisa $100 \%$ di akhir tahun 2019. Perlu diketahui sebelumnya, Kabupaten Tegal berada pada peringkat ke 32 dari 35 Kabupaten/ Kota. Hal ini diperkuat dengan pernyataan Bapak Taufik dalam wawancara :

"Makanya untuk desa yang ada di pinggiran sungai menjadi permasalahan yang kompleks itu. Jadi memang komitmen Ibu Bupati telah menyampaikan pokoknya 2019 harus ODF Kabupaten Tegal, karena di Jawa Tengah itu baru 7. Kalau tahun kemarin 2017 kita masih rangking 32 sekarang sudah rangking 23 pada tahun 2018. Dulu sebelum ada PDPM kita rangking 32 dari 35 kabupaten berdasarkan akses sanitasinya. Sekarang kita sudah di posisi $85 \%$ akses sanitasinya. Jadi sanitasi yang diperbaiki itu ada dua yaitu sarana sama aksesnya. Dan kita tetap menjalin dengan pihak-pihak lain agar dapat mempercepat target" 
Menuju angka 100\% ODF, Dinas Kesehatan Kabupaten Tegal sebagai pelaksana program kerja ini tetap menggandeng pihak lain. Bentuk dukungan lain yang diberikan yakni membentuk kerja sama dan koordinasi dengan pihak lain yang terkait dalam pelaksanaan program ini. Adapun pihak lain yang tekait dengan pelaksanaan program PDPM pembangunan jamban sehat seperti :

a. Dinas Perumahan Rakyat, Kawasan Permukiman, Tata Ruang dan Pertanahan Kabupaten Tegal

b. Badan Perencanaan Pembangunan, Penelitian dan Pengembangan Daerah Kabupaten Tegal

c. Dinas Pemberdayaan Masyarakat dan Desa

d. Badan Pengelolaan Keuangan dan Aset Daerah;

e. Inspektorat Kabupaten Tegal

f. Kecamatan dan Puskesmas di Kabupaten Tegal

g. Pemerintahan Desa

Implementasi PDPM ini semakin didukung dengan dirancangnya Renstra sebagai penetapan implementasi strategi Dinas Kesehatan Kabupaten Tegal. Renstra memuat referensi indikator outcome bagi pimpinan dalam jangka waktu lima tahun. Rencana strategis ini dirancang agar dapat mempercepat pemenuhan target capaian. Berdasarkan profil kesehatan Kabupaten Tegal, kasus diare yang ditemukan dan ditangani di Kabupaten Tegal tahun 2015 mencapai 195,3\%. Angka ini sudah memenuhi target SPM dan Renstra Dinas Kesehatan Kabupaten Tegal yaitu 100\% Incidence Rate diare Kabupaten Tegal tahun 2014 sebesar 214 per 1000 penduduk.

KASUS DIARE YANG DITANGANI MENURUT JENIS KELAMIN, KECAMATAN, DAN PUSKESMAS KABUPATEN TEGAL TAHUN 2015

\begin{tabular}{|c|c|c|c|c|c|c|c|c|c|c|c|c|c|c|}
\hline \multirow{2}{*}{ No } & \multirow{2}{*}{ KECAMATAN } & \multirow{2}{*}{ PUSKESMAS } & \multicolumn{3}{|c|}{ JUMLAH PENDUDUK } & \multicolumn{3}{|c|}{$\begin{array}{l}\text { JUMLAH TARGET } \\
\text { PENEMUAN }\end{array}$} & \multicolumn{4}{|c|}{ DIARE DITANGANI } & \\
\hline & & & $\mathrm{L}$ & $P$ & $L+P$ & L & $\mathrm{P}$ & $L+P$ & JUMLAH & $\%$ & JUMLAH & $\%$ & JUMLAH & $\%$ \\
\hline & $\frac{2}{2}$ & $\frac{3}{\text { Margasari }}$ & $\frac{4}{26,450}$ & \begin{tabular}{|l|}
5 \\
25.818 \\
\end{tabular} & $\begin{array}{ll}6 \\
52,268\end{array}$ & & $\frac{8}{553}$ & $\begin{array}{ll}9 \\
1,119\end{array}$ & $\frac{10}{10}$ & $\frac{117}{112}$ & 12 & 13 & $\begin{array}{ll}14 \\
1.294 \\
\end{array}$ & $\frac{15}{116}$ \\
\hline $\begin{array}{l}1 \\
2 \\
\end{array}$ & & Kesambi & 21.242 & 20.702 & 41,944 & $\begin{array}{l}455 \\
455 \\
\end{array}$ & $\begin{array}{l}5533 \\
443\end{array}$ & $\begin{array}{r}1,199 \\
898\end{array}$ & $\begin{array}{l}634 \\
467\end{array}$ & $\begin{array}{l}112 \\
103\end{array}$ & $\begin{array}{r}660 \\
508 \\
.07\end{array}$ & 115 & 975 & 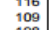 \\
\hline & $\begin{array}{l}\text { Bumijawa } \\
\text { Bojong }\end{array}$ & \begin{tabular}{|l} 
Buminjawa \\
Bojong
\end{tabular} & $\begin{array}{l}42,939 \\
22,662\end{array}$ & $\begin{array}{l}39.586 \\
22,117\end{array}$ & $\begin{array}{l}81,525 \\
44,779\end{array}$ & $\begin{array}{l}897 \\
485 \\
895\end{array}$ & $\begin{array}{l}887 \\
473\end{array}$ & $\begin{array}{r}1,775 \\
958\end{array}$ & $\begin{aligned} 1,674 \\
577\end{aligned}$ & $\begin{array}{l}\begin{array}{l}187 \\
119\end{array} \\
\end{array}$ & $\begin{array}{l}1,777 \\
513\end{array}$ & $\begin{array}{l}210 \\
108\end{array}$ & $\begin{array}{l}3,451 \\
1,090\end{array}$ & $\begin{array}{l}198 \\
114\end{array}$ \\
\hline & & Danasari & 11,000 & & 21,436 & 235 & 223 & 459 & 30 & 13 & & & $\begin{array}{r}69 \\
-170\end{array}$ & \\
\hline & Balapulang & \begin{tabular}{|l} 
| alalaulang \\
Kalibakung
\end{tabular} & $\begin{array}{l}25,2826 \\
22,280\end{array}$ & $\begin{array}{l}24,299 \\
21,134\end{array}$ & $\begin{array}{l}50,125 \\
43,414\end{array}$ & 4777 & ${ }_{452}^{520}$ & 1,073 & $\begin{array}{l}385 \\
950\end{array}$ & $\begin{array}{c}70 \\
199\end{array}$ & $\begin{array}{l}486 \\
989\end{array}$ & $\begin{array}{r}93 \\
219\end{array}$ & $\begin{array}{r}87.939 \\
1.939\end{array}$ & $\begin{array}{r}81 \\
209\end{array}$ \\
\hline 8 & Pagerbarang & Pagerbarang & 28,278 & 28,001 & 56.279 & 605 & 599 & 1.204 & 1.611 & 266 & 1,708 & 285 & 3,319 & 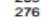 \\
\hline $\begin{array}{c}9 \\
10\end{array}$ & Lebaksiu & \begin{tabular}{|l|}
$\mid$ Lebaksiu \\
Kambangan
\end{tabular} & $\begin{array}{l}25.865 \\
17,199\end{array}$ & $\begin{array}{l}25.521 \\
17.620\end{array}$ & $\begin{array}{l}\begin{array}{l}51,386 \\
34,819\end{array} \\
\end{array}$ & $\begin{array}{l}564 \\
368 \\
\end{array}$ & $\begin{array}{l}546 \\
377\end{array}$ & $\begin{array}{l}1,100 \\
745\end{array}$ & $\begin{array}{l}640 \\
777\end{array}$ & $\begin{array}{l}116 \\
211\end{array}$ & $\begin{array}{l}972 \\
828\end{array}$ & $\begin{array}{l}178 \\
220\end{array}$ & $\begin{array}{l}1,612 \\
1,605\end{array}$ & $\begin{array}{l}147 \\
215\end{array}$ \\
\hline 11 & Jatinegara & Jatinegara & 28,690 & 27.289 & 55,979 & 614 & 584 & 1,198 & 927 & 151 & 1,256 & 215 & 2,183 & 182 \\
\hline & $\begin{array}{l}\text { Kedungbanteng } \\
\text { Pangkah }\end{array}$ & Peoungoditieng & & & & 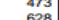 & 4661 456 & 1029 & & & 1.974 & & & 195 \\
\hline 14 & s. & Penusupan & 19,118 & 18,830 & 37.948 & 409 & ${ }_{403}>3$ & 812 & 555 & 136 & 844 & 209 & 1399 & 年 \\
\hline 15 & Slawi & Slawi & 30,794 | ب | & 31,745 & 62,539 & 659 & 679 & 1,338 & 660 & 100 & 974 & 143 & & \\
\hline & Dukuthraru & Dukutwaru & 年 29.016 & 年, 82,824 & S67.840 & 6211 & 617 & 1.238 & 772 & 124 & 960 & 156 & 1,732 & 140 \\
\hline & ponverias & Paoivanten & & & & & & 916 & 509 & & & & & \\
\hline 19 & Dukuhturi & Dukunturi & 26,678 & 25,638 & 52,316 & 571 & 549 & 1,120 & 454 & 80 & 551 & 100 & 1,005 & 90 \\
\hline 20 & & Kupu & 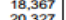 & 17.457 & 染, 35,824 & 䏛3 & 374 & 787 & 7099 & 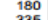 & . & 1966 & $\begin{array}{l}1,443 \\
1,450\end{array}$ & 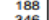 \\
\hline & 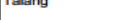 & Tralang & & 193.495 & & 50. & & 8042 & 1,456 & & & & & \\
\hline 23 & Tarub & Tarub & 24,559 & 23,966 & 48,525 & 526 & 513 & 1,038 & 1,907 & 363 & 2,049 & 400 & 3,956 & 381 \\
\hline & Kramat & $\begin{array}{l}\text { Kesamiran } \\
\text { Kramat }\end{array}$ & $\begin{array}{l}13,083 \\
26,193\end{array}$ & $\begin{array}{l}12,858 \\
27,431\end{array}$ & $\begin{array}{l}25,941 \\
53,624\end{array}$ & 561 & $\begin{array}{l}275 \\
587\end{array}$ & $\begin{array}{l}555 \\
1.148\end{array}$ & $\begin{array}{l}1,218 \\
1,230\end{array}$ & $\begin{array}{l}364 \\
219\end{array}$ & $\begin{array}{l}1.052 \\
1,534\end{array}$ & 261 & $\begin{array}{l}2,070 \\
2,764\end{array}$ & $\begin{array}{l}373 \\
2_{244}\end{array}$ \\
\hline 26 & & Bangun Galih & $16.553]$ & 17.058 & 33,611 & 354 & 365 & 7719 & 876 & ${ }_{247}$ & 871 & 239 & 1,747 & ${ }_{243}^{243}$ \\
\hline $\begin{array}{l}27 \\
28\end{array}$ & Suradadi & \begin{tabular}{|l} 
Suradadi \\
Jatitiogogor
\end{tabular} & $\begin{array}{l}23,894 \\
21,069\end{array}$ & $\begin{array}{l}22,802 \\
20,338\end{array}$ & $\begin{array}{l}46,696 \\
41,407\end{array}$ & 511 & $\begin{array}{l}488 \\
435 \\
435-10\end{array}$ & 999 & $\begin{array}{l}775 \\
827\end{array}$ & 152 & $\begin{array}{r}858 \\
1043 \\
\end{array}$ & $\begin{array}{c}176 \\
240\end{array}$ & $\begin{array}{l}1,633 \\
1,870\end{array}$ & $\begin{array}{l}163 \\
1631 \\
211\end{array}$ \\
\hline 29 & Warureja & Warureja & 28,939 & 28,109 & 57,048 & 619 & 602 & 1,221 & 845 & $\begin{array}{l}136 \\
136\end{array}$ & $\begin{array}{lll}837 \\
837\end{array}$ & 139 & $\begin{array}{l}1,682 \\
1,180\end{array}$ & 138 \\
\hline \multirow{2}{*}{\multicolumn{3}{|c|}{ UMLAH (K) }} & 701,920 & 684.894 & 1,386,814 & 15,021 & 14.657 & 29,678 & 27,491 & 183.0 & 30,461 & 207.8 & 57,952 & 195.3. \\
\hline & & & & & & & & & & & & & & \\
\hline
\end{tabular}

Tabel 2. Profil Kesehatan Kab. Tegal tahun 2015 
Berdasarkan Tabel 2 di atas penderita diare di setiap kecamatan tergolong masih cukup tinggi. Pemerintah Kabupaten Tegal yakin dan berkomitmen penuh untuk dapat menyukseskan program pemerintah dalam meningkatkan peningatan kebutuhan sanitasi dengan melaksanakan program STBM. Diawali dengan implementasi pilar pertama STBM yakni Stop BABS atau ODF. Program ini menjadi pekerjaan rumah yang harus benar-benar dibenahi oleh Pemerintah Kabupaten Tegal. Hingga tahun 2017, diketahui banyak masyarakat yang tinggal dekat dengan aliran sungai dan masih belum memiliki jamban. Mirisnya di Kecamatan Slawi yang merupakan ibu kota Kabupaten Tegal masih ditemukan banyak warga yang belum memiliki jamban sehat seperti pada tabel di bawah:

\begin{tabular}{|c|c|c|}
\hline \multicolumn{3}{|c|}{ JUMLAH KK PENERIMA PDPM DI KEC. SLAV } \\
\hline NO & NAMA DESA & $\begin{array}{c}\text { JUMLAH } \\
\text { PENERIMA }\end{array}$ \\
\hline 1. & SLAWI KULON & $34 \mathrm{KK}$ \\
\hline 2. & TRAYEMAN & $21 \mathrm{KK}$ \\
\hline 3. & DUKUHSALAM & $40 \mathrm{KK}$ \\
\hline 4. & DK. WRINGIN & $42 \mathrm{KK}$ \\
\hline 5. & KALISAPU & $47 \mathrm{KK}$ \\
\hline & JUMLAH & $184 \mathrm{KK}$ \\
\hline
\end{tabular}

Tabel 3 Sumber : Laporan Dinas Kesehatan Kabupaten Tegal

Terdapat kurang lebih $184 \mathrm{KK}$ yang belum memiliki jamban sehat di Kecamatan Slawi yang tersebar di lima desa. Agar lebih mudah diingat masyarakat, program ini diperkenalkan dengan istilah "Jambanisasi". Peran, dukungan serta kerja sama dari pemerintah daerah sangat penting dalam pelaksanaan pemicuan STBM.

\section{Demand}

Program Jambanisasi dijadikan salah satu program pemberdayaan agar dapat melibatkan berbagai pihak, termasuk partisipasi masyarakat itu sendiri. Indikator keberhasilan Kabupaten Tegal dinyatakan open defecation free, ketika tidak ditemukan lagi data masyarakat yang masih BABS. Permasalahan yang ditemukan ternyata bukan sekedar itu, terdapat beberapa masalah lain seperti yang diungkapkan pada wawancara oleh Bapak Tofiq:

“Terus permasalahan lain untuk desa desa yang ada aliran sungai itu menjadi permasalahan yang rumit juga kalau sekedar tidak punya kemudian membangunkan kan itu mudah. Tapi kalau rumah-rumah yang pinggiran bantaran sungai rata-rata tidak punya septic tank dialirkan ke sungai baik dari kamar mandi, satu paralon kamar mandi, wc langsung ke sungai itu kan sama saja BABS di sungai tapi ditutupin. Makanya untuk 
desa yang ada di pinggiran sungai ya permasalahan yang kompleks itu”

Di beberapa wilayah terdapat masyarakat yang tergolong mampu dan sudah memiliki jamban, namun tidak memiliki septictank sehingga kotoran langsung mengalir ke sungai. Masalah tersebut menjadi tantangan bagi pelaksana program untuk mencari solusi dalam penuntasannya. Memasuki komponen STBM kedua yakni demand atau peningkatan kebutuhan sanitasi di masyarakat. Demand dapat diimplementasikan dengan metode pemicuan yang ada pada STBM. Pemicuan merupakan metode pemberdayaan masyarakat dengan tujuan agar masyarakat secara sadar memahami konsep sanitasi sehat dan terpicu untuk memiliki jamban secara mandiri. Pemicuan dilakukan oleh para fasilitator di masing-masing wilayah kerjanya. Fasilitator ini termasuk para sanitarian yang ada di puskesmas. Mereka melakukan sosialisasi, penyuluhan, pelatihan, diskusi hingga simulasi secara terus menerus hingga pada akhirnya masyarakat terpicu membutuhkan jamban sehat.

PDPM juga mengimplementasikan metode pemicuan karena memang program ini dirancang untuk mendukung keberhasilan STBM. Bisa disimpulkan bahwa pemicuan termasuk dalam teknik komunikasi pemberdayaan. Dalam melaksanakan suatu program pemberdayaan masyarakat, tentu tidak terlepas dari peran komunikasi. Komunikasi dinilai sangat penting untuk keberlangsungan program. Untuk itu, didalam pelaksanaan komunikasi pemberdayaan dikenal dengan istilah saluran komunikasi. Saluran komunikasi pada pelaksanaan program PDPM Jambanisasi adalah komunikasi interpersonal, sosialisasi lintas sektor tingkat kabupaten dan kecamatan, event khusus seperti deklarasi desa ODF, pamflet dan poster, media massa seperti radio dan surat kabar.

Upaya-upaya ini dikerahkan langsung dengan komunikasi pemberdayaan agar tujuan program tersebut dapat tercapai. Seperti yang diungkapkan oleh Bapak Nuryadi bahwasannya :

"Nah PDPM menjadi pendukung di tingkat daerah khusunya Kabupaten Tegal untuk mendukung salah satu pilar STBM yakni stop BABS. PDPM itu kebijakan daerah hanya ada di Kabupaten Tegal, sedangkan pelaksanaan STBM tetap berlaku nasional. Pemicuan itu menjadi bagian yang paling teknis dalam STBM. Pemicuan bisa dilakukan dengan berbagai media komunikasi. Pemicuan adalah metode pemberdayaan masyarakat sebenarnya. Nah pemicuan ini adalah salah satu upaya menyadarkan masyarakat agar masyarakat tahu dan faham secara mandiri. Konsep dasarnya STBM itu tidak boleh memberikan bantuan maka dari itu disebut mandiri. Rohnya STBM adalah pemicuan, bagaiamana kita menggerakan masyarakat secara mandiri, memberdayakan masyarakat agar mandiri agar sadar kalau kita ngomong pilar satu bahwa jamban sehat 
itu mutlak dibutuhkan bagi masyarakat dan dibutuhkan untuk saya. “

Metode pemicuan yang disampaikan di atas, tidak hanya digerakkan dengan komunikasi tatap muka baik interpersonal maupun antar kelompok. Penggunaan media sebagai alat komunikasi juga melengkapi proses pemicuan guna menciptakan kebutuhan sanitasi masyarakat. Berikut contoh media poster yang digunakan dalam rangka pemicuan kepada masyarakat :
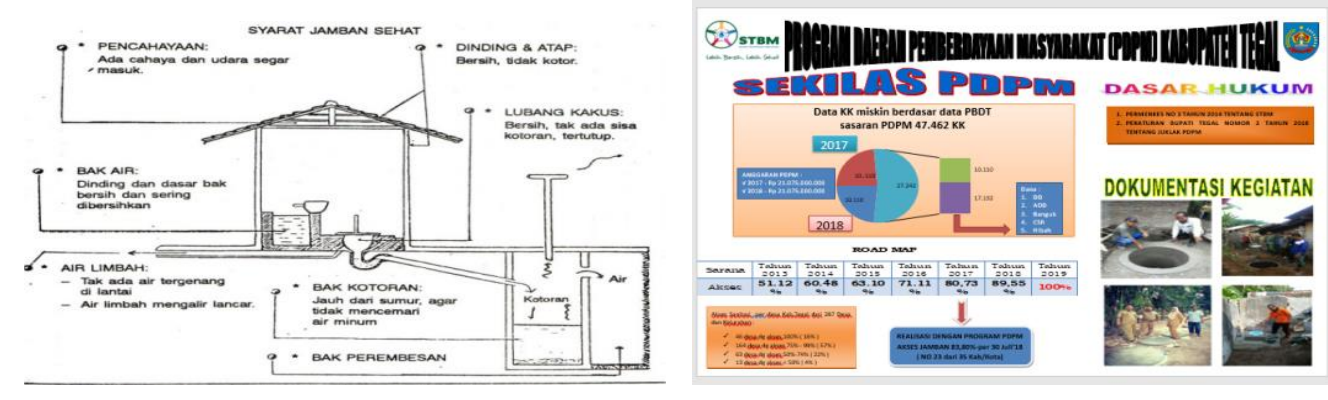

Gambar 1 Media Kampanye PDPM dan Pemicuan STBM

\section{Supply}

Komponen ketiga adalah supply atau pemenuhan kebutuhan dan penyediaan akan produk-produk sanitasi yang terjangkau. Komponen ini adalah finishing dalam STBM yakni masyarakat yang terpicu membangun jamban sehat dan meninggalkan perilaku BABS. Seperti yang telah dijelaskan sebelumnya bahwa tujuan program pemberdayaan masyarakat adalah mengembangkan dan meningkatkan kualitas hidup masyarakat agar dapat mandiri dan dapat mengatasi persoalan kehidupannya. Kondisi semacam ini akan memberikan peluang besar kepada masyarakat untuk meningkatkan kemampuan dan kapasitasnya dalam bidang ekonomi, pendidikan, sosbud, dan politik dalam kehidupan bersama. Hal tersebut merupakan pertimbangan Pemkab. Tegal dalam mengusung PDPM Jambanisasi melihat kondisi masyarakat dan tuntutan Kabupaten ODF.

Kondisi yang penulis maksud adalah kebiasaan masyarakat yang masih menganggap wajar perilaku BABS. Kondisi memprihatinkan masih terlihat di wilayah Kecamatan Adiwerna. Budaya Buang Air Besar Sembarangan (BABS) hingga kini masih dilakukan sebagian warga yang berdiam di 21 desa dan total keluarga yang belum memiliki jamban sehat mencapai 3.849. Kecamatan Adiwerna merupakan kecamatan yang paling berdekatan dengan Ibukota Kabupaten Tegal, bisa disebut sebagai serambinya Kabupaten Tegal. Berikut data penerima manfaat jamban sehat per kecamatan di Kabupaten Tegal : 


\begin{tabular}{|c|c|c|c|c|c|c|c|c|c|c|}
\hline No & PUSKESMAS & KECAMATAN & $\begin{array}{c}\text { JUML } \\
\text { AH } \\
\text { DESA }\end{array}$ & $\begin{array}{c}\text { DESA } \\
\text { SELESAI }\end{array}$ & $\begin{array}{l}\text { DESA } \\
\text { (SILP } \\
\text { A) }\end{array}$ & $\begin{array}{c}\text { JML } \\
\text { PENERI } \\
\text { MA } \\
\text { MANFAA } \\
\text { T } \\
\end{array}$ & $\begin{array}{c}\text { JAMBAN } \\
\text { TERBANG } \\
\text { UN }\end{array}$ & $\begin{array}{c}\text { KEKU } \\
\text { RANG } \\
\text { AN }\end{array}$ & \begin{tabular}{|c|} 
DES \\
A \\
BLM \\
SEL \\
ESAI
\end{tabular} & $\begin{array}{c}\text { PERS } \\
\text { ENTA } \\
\text { SI }\end{array}$ \\
\hline 1 & Bumijawa & Bumijawa & 18 & 18 & & 649 & 649 & $\mathrm{O}$ & $\mathrm{O}$ & 0,00 \\
\hline 2 & Bojong & Bojong & 9 & 9 & & 262 & 262 & $\mathrm{O}$ & $\mathrm{O}$ & 0,00 \\
\hline 3 & \begin{tabular}{|l|} 
Danasari \\
\end{tabular} & \begin{tabular}{|l|} 
Bojong \\
\end{tabular} & 8 & 8 & & 189 & 189 & $\mathrm{O}$ & $\mathrm{O}$ & $\mathrm{O}, \mathrm{OO}$ \\
\hline 4 & Jatinegara & Jatinegara & 17 & 17 & & 574 & 615 & $\mathrm{O}$ & $\mathrm{O}$ & $\mathrm{O}, \mathrm{OO}$ \\
\hline 5 & Kedungbanten & Kedungbanter & 10 & 8 & 2 & 433 & 399 & 34 & 2 & 20,00 \\
\hline 6 & Pangkah & Pangkah & 14 & 13 & 1 & 466 & 449 & 17 & 1 & 7,14 \\
\hline 7 & Penusupan & Pangkah & 9 & 8 & 1 & 314 & 308 & 6 & 1 & 11,11 \\
\hline 8 & \begin{tabular}{|l|} 
Tarub \\
\end{tabular} & Tarub & 12 & 12 & & 476 & 476 & $\mathrm{O}$ & $\mathrm{O}$ & $\mathrm{O}, \mathrm{OO}$ \\
\hline 9 & Kesamiran & Tarub & 8 & 8 & & 268 & 268 & $\mathrm{O}$ & $\mathrm{O}$ & 0,00 \\
\hline 10 & Kramat & Kramat & 10 & 8 & 1 & 351 & 334 & 17 & 2 & 20,00 \\
\hline 11 & Bangungalih & Kramat & 9 & 9 & & 339 & 339 & $\mathrm{O}$ & $\mathrm{O}$ & $\mathrm{O}, \mathrm{OO}$ \\
\hline 12 & Suradadi & Suradadi & 5 & 5 & & 223 & 223 & $\mathrm{O}$ & $\mathrm{O}$ & 0,00 \\
\hline 13 & Jatibogor & Suradadi & 6 & 6 & & 243 & 243 & $\mathrm{O}$ & $\mathrm{O}$ & $\mathrm{O}, \mathrm{OO}$ \\
\hline 14 & Warureja & Warureja & 12 & 12 & & 561 & 563 & $\mathrm{O}$ & $\mathrm{O}$ & 0,00 \\
\hline 15 & Dukuhturi & \begin{tabular}{|l} 
Dukuhturi \\
\end{tabular} & 11 & 11 & & 179 & 179 & $\mathrm{O}$ & $\mathrm{O}$ & 0,00 \\
\hline 16 & \begin{tabular}{|l|} 
Kupu \\
\end{tabular} & Dukuhturi & 7 & 6 & & 170 & 147 & 23 & 1 & 14,29 \\
\hline 17 & Talang & Talang & 10 & 10 & & 290 & 280 & 10 & $\mathrm{O}$ & $\mathrm{O}, \mathrm{OO}$ \\
\hline 18 & Kaladawa & \begin{tabular}{|l} 
Talang \\
\end{tabular} & 9 & 9 & & 322 & 322 & $\mathrm{O}$ & $\mathrm{O}$ & 0,00 \\
\hline 19 & Adiwerna & Adiwerna & 10 & 9 & 1 & 369 & 322 & 47 & 1 & 10,00 \\
\hline 20 & Pagiyanten & Adiwerna & 11 & 8 & 3 & 390 & 306 & 84 & 3 & 27,27 \\
\hline 21 & Dukuhwaru & Dukuhwaru & 10 & 10 & & 401 & 444 & $\mathrm{O}$ & $\mathrm{O}$ & $\mathrm{O}, \mathrm{OO}$ \\
\hline 22 & Pagerbarang & Pagerbarang & 13 & 11 & 1 & 543 & 479 & 64 & 2 & 15,38 \\
\hline 23 & Lebaksiu & Lebaksiu & 8 & 8 & & 342 & 342 & $\mathrm{O}$ & $\mathrm{O}$ & 0,00 \\
\hline 24 & Kambangan & Le baksiu & 7 & 7 & & 346 & 347 & $\mathrm{O}$ & $\mathrm{O}$ & 0,00 \\
\hline 25 & Balapulang & Balapulang & 9 & 8 & & 385 & 377 & 8 & 1 & 11,11 \\
\hline 26 & Kalibakung & Balapulang & 11 & 11 & & 460 & 460 & $\mathrm{O}$ & $\mathrm{O}$ & $\mathrm{O}, \mathrm{OO}$ \\
\hline 27 & Margasari & Margasari & 7 & 7 & & 307 & 314 & $\mathrm{O}$ & $\mathrm{O}$ & $\mathrm{O}, \mathrm{OO}$ \\
\hline 28 & Kesambi & Margasari & 6 & 6 & & 234 & 240 & $\mathrm{O}$ & $\mathrm{O}$ & 0,00 \\
\hline 29 & Slawi & Slawi & 5 & 5 & & 176 & 176 & $\mathrm{O}$ & $\mathrm{O}$ & $\mathrm{O}, \mathrm{OO}$ \\
\hline & \multicolumn{2}{|c|}{ TOTA } & 281 & 267 & 10 & 10262 & 10052 & 310 & 14 & 4,98 \\
\hline & & 95,02 & 3,56 & & 97,95 & & & \\
\hline
\end{tabular}

Tabel 4 Data Penerima Jamban Sehat di Setiap Kecamatan di Kabupaten Tegal

Terlihat pada tabel 4 wilayah Adiwerna memiliki penerima manfaat terbanyak. Di Kecamatan Adiwerna, desa yang masyarakatnya paling banyak melakukan budaya BABS hingga saat ini tercatat Harjosari Kidul dengan jumlah KK tidak memiliki jamban sebanyak 1.875 KK. Demi keberhasilan implementasi PDPM Jambanisasi, Camat Adiwerna berupaya untuk mengucurkan dana desa $100 \%$ untuk percepatan mewujudkan desa open defecation free. Tercatat wilayah dengan progres pembangunan jamban sehat yang baik yakni Kecamatan Pagerbarang. Di mana dari target 646 penerima manfaatnya sudah terealisasi 476, Artinya sudah mencapai $73,68 \%$.

Target $100 \%$ akan dicapai pada tahun 2019, dengan rincian pada tahun 2017 yakni 16.787 paket pekerjaan jamban sehat untuk mencapai 80 persen, tahun 2018 berlanjut untuk 18.392 paket pekerjaan jambanisasi menuju persentase $89 \%$, dan di tahun 2019 pekerjaan paket mencapai 21.795 untuk mencapai $100 \%$ desa bebas dari budaya BABS. Meskipun pelaksanaan PDPM jambanisasi masih belum optimal, namun progres yang ditunjukkan sangat baik. Dibuktikan dengan prestasi yang berhasil diraih oleh Kabupaten Tegal dalam mewujudkan Kabupaten ODF. Implementasi PDPM menuju Kabupaten Tegal ODF 2019 tidak hanya dilakukan dengan menerapkan tiga komponen STBM saja. Melalui PDPM, Kabupaten Tegal berhasil menciptakan Paguyuban Wirausaha Sanitasi. Program Pemberdayaan ini bukan hanya membuat masyarakat berdaya dalam bidang kesehatan tetapi sekaligus berupaya membangun ekonomi masyarakat. Seperti yang disampaikan oleh Bapak Thaufiq dalam wawancara :

"Kalau pelatihan bentuknya teknik cara membuat jamban sudah sejak tahun 2015 kita adakan di seluruh seluruh desa jumlahnya 281 kita undang kesini, kemudian kita latih bagaiamana cara membuat jamban kemudian 
kita praktek ke lapangan proses pembuatannya. Dulu sebelum adanya PDPM beberapa desa mereka biasanya menggunakan arisan jamban sebesar 1,2 juta yang dikelola oleh desa. Sekarang dengan adanya PDPM akhirnya mendapatkan bantuan ini. Hanya desa tertentu yang ada arisan tergantung keaktifan sanitarian puskesmas"

Proses pemberdayaan dengan membentuk paguyuban sanitasi ini dilakukan setelah melakukan sosialisasi dan membentuk tim koordinasi baik di tingkat kabupaten maupun kecamatan, selanjutnya dibentuklah tim koordinasi di tingkat desa dengan nama paguyuban wirausaha sanitasi. Paguyuban ini terbentuk dengan cara memberikan sosialisasi dan pelatihan bagi tukang batu desa setempat, tentang keuntungan serta pembuatan jamban sehat dengan teknik yang benar.

Leading sector dalam pemberdayan ini adalah Dinas Kesehatan. Pelatihan ini diikuti oleh tukang batu, tenaga sanitarian puskesmas, tokoh masyarakat, dan pengelola Pamsimas. Wirausaha sanitasi merupakan upaya yang menitikberatkan program sanitasi berbasis masyarakat seperti pembuatan kloset sederhana dan jamban sehat. Proses pembelajarannya dimulai dengan konsep dasar wirausaha sanitasi, jejaring sanitasi, pengenalan produk/jasa sanitasi hingga praktek langsung di lapangan. Jadi PDPM ini selain mengajak masyarakat untuk ODF, sekaligus berusaha mengajak masyarakat memperbaiki kondisi ekonomi dengan menjadi wirausaha sanitasi. PDPM ini terlaksana dengan memberdayakan tukang batu setempat yang sudah terlatih. Menurut pengakuan Bapak Nuryadi selaku programmer PDPM, dalam implementasi program ini masih banyak ditemukan kendala. Berikut pernyataan beliau :

"Fokus program ini untuk 281 Desa dan enam kelurahan. Kalau dari tingkat kecamatan kurang aktifnya tim koordinasi dalam melakukan monitoring dan evaluasi sehingga pelaksanaannya kadang banyak kendala. Kemudian data PBDT tidak update kadang menjadi sulit untuk memenuhi tiga harapan utama dalam PDPM ini yakni tepat mutu, sasaran dan manfaat. Kesadaran masyarakat masih sulit kita bangun harus pemicuan secara terus tanpa lelah baik kepada masyarakat yang belum punya jamban maupun sudah punya tanpa septic tank."

Implementasi PDPM masih menemui permasalahan yang berkaitan dengan pemicuan, kemutakhiran data penerima manfaat, bahkan pasca pembuatan jamban. Ke depannya Pemerintah Kabupaten Tegal melalui dinas terkait selalu berupaya untuk melakukan perbaikan dalam implementasi program kerja ini.

Kabupaten Tegal tengah berupaya semaksimal mungkin untuk mewujudkan pilar pertama STBM yakni stop buang air besar sembarangan atau STOP BABS. Stop BABS ini dilakukan dengan pembangunan jamban sehat di 281 desa dan enam kelurahan di 18 kecamatan se-Kabupaten Tegal. Bukan tidak mungkin luasnya wilayah, jumlah masyarakat, dan kebiasaan BABS masyarakat menimbulkan masalah yang menjadi hambatan pelaksanaan program jambanisasi 
ini. Kemudian muncul pertanyaan bagaimana proses pelaksanaan tersebut, serta apa yang dilakukan pemerintah agar kebijakan dan jambanisasi ini dapat diterima oleh masyarakat. Secara regulasi, kemudian pelaksanaan STBM diatur dalam Perbup tentang Petunjuk Pelaksanaan PDPM.

Pemberdayaan sebagai wujud upaya untuk memberikan kekuatan, meningkatkan kemampuan dan potensi yang dimiliki oleh individu maupun kelompok yang lemah (miskin) hingga menyadari potensi yang dimiliki dan berupaya untuk meninggalkan keadaan keterbelakangan sebelumnya. Ini sesuai dengan pendapat dari Istiyanto (2017) yang menyebutkan pemberdayaan sebagai usaha untuk menjadikan keadaan masyarakat lebih baik dari sebelum diberdayakan. Tepat apabila program STBM ini menjadi salah satu program pemberdayaan. Tujuan utama dari STBM adalah menjadikan masyarakat sadar akan pentingnya kesehatan sanitasi dan meninggalkan perilaku BABS. Melalui implementasi PDPM ini berupaya menunjukkan perannya untuk memberikan kekuatan agar masyarakat mau dan mampu meninggalkan keterbelakangan. Oleh sebab itu, dalam proses pemberdayaan sangat penting adanya partisipasi masyarakat guna mengidentifikasi masalah dan potensi yang ada di masyarakat sesuai dengan pendapat Adi (2007). Senada dengan itu bahwa keterlibatan partisipasi masyarakat dapat menjadikan program pemberdayaan masyarakat berjalan dengan lebih baik karena, akan menimbulkan rasa kepemilikan atas program pemberdayaan tersebut (Istiyanto, 2017 : 47)

Metode pemicuan dalam STBM tidak dapat berjalan jika tidak ada partisipasi masyarakat. Implementasi PDPM Jambanisasi di Kabupaten Tegal berjalan tanpa menghilangkan metode pemicuan dan tiga komponen utama yang ada pada STBM. Apabila ditarik garis merah, sebenarnya antara PDPM dan STBM memiliki konsep yang berbeda. Konsep pemikiran dan penerapan pelaksanaan dua program tersebut justru bertolak belakang. Implementasi PDPM dilakukan dengan wujud pemberian bantuan berupa pembangunan jamban sehat untuk masyarakat miskin. Jauh berbeda dengan konsep pemikiran pada pelaksanaan STBM yang sebenarnya melarang pemerintah untuk memberikan bantuan dalam bentuk apa pun.

Dalam STBM prinsip pelaksanaannya adalah membangun kesadaran masyarakat agar terpicu untuk meningkatkan akses sanitasi sehat secara mandiri. Teknik pemicuan yang dibahas di atas adalah salah satu metode yang digunakan dalam memberdayakan masyarakat. Mengikuti pendapat Widjajanti (2011) proses pemberdayaan dapat diwujudkan bila adanya partisipasi masyarakat dalam prosesproses pembangunan yang dilakukan oleh pemerintah yang menjadi faktor pemicu. Pemicuan ini menarik ketersediaan masyarakat dalam berpartisipasi dengan mengkomunikasikannya terlebih dahulu kepada masyarakat.

Hal ini dapat dianalisis pemicuan yang dilakukan tanpa memberikan 
bantuan merupakan wujud pemicuan STBM total. Sejauh ini hanya Pemerintah Kabupaten Grobogan yang menerapkan pemicuan STBM total. Sejak dikeluarkanya Instruksi Bupati Tegal No. 440/2500 Tahun 2014, kemudian disusul dengan Perbup No. 2 Tahun 2018 Tentang Juklak PDPM. Implementasi PDPM Pemerintah Kabupaten Tegal sudah baik dari proses tahapan yang dijalankan. Pelaksanaan PDPM menjanjikan hasil yang signifikan. Dibuktikan dengan kenaikan peringkat akses sanitasi yang berhasil diraih Kabupaten Tegal dalam dua tahun.

Terwujudnya program pemberdayaan dan keswadayaan masyarakat dengan sistem swakelola pada PDPM Jambanisasi. Pemerintah juga memberikan pelatihan bagi tukang batu desa setempat. Hal ini bertujuan agar PDPM Jambanisasi bukan hanya mempercepat target Kabupaten ODF, tetapi juga dapat memperbaiki kondisi ekonomi masyarakat di desa. Pemberdayaan masyarakat ini dapat memenuhi harapan pelaksanaan PDPM Jambanisasi agar dapat memenuhi 3 aspek tepat yaitu : tepat mutu, tepat sasaran, dan tepat manfaat. Meskipun begitu kenyataan di lapangan tetap ditemukan adanya hambatan. Hambatan dalam implementasi program ini, terjadi baik pada penetapan sasaran, pencairan anggaran, bahkan pasca pembangunan jamban. Penetapan sasaran dan anggaran terkendala karena PBDT sebagai acuan data terkadang tidak valid. Pemicuan tetap dilakukan pasca pembangunan jamban dengan teknik monitoring dan evaluasi (monev) setiap bulan oleh sanitarian. Mengoptimalkan peran pemerintah dalam implementasi PDPM Jambanisasi agar tahun 2019 Kabupaten Tegal berhasil meraih predikat sebagai Kabupaten ODF.

\section{SIMPULAN}

Program Daerah Pemberdayaan Masyarakat (PDPM) sebagai salah satu program unggulan Kabupaten Tegal. Program ini difokuskan untuk penataan dan penyehatan lingkungan khususnya peningkatan akses sanitasi dengan pembuatan jamban sehat bagi masyarakat miskin. Melalui PDPM Jambanisasi ini diharapkan mampu mewujudkan Kabupaten Tegal Open Defecation Free di tahun 2019. Kabupaten Tegal berhasil memadukan dua program dengan dua konsep yang berbeda yakni STBM dan PDPM. Impelemtasi PDPM Jambanisasi dilakukan dengan tetap menggunakan teknik pemicuan, menggunakan tiga komponen utama STBM yakni enabling environment, demand, dan supply agar dapat memenuhi harapan pelaksanaan PDPM yakni tepat sasaran, mutu dan manfaat. Perilaku BABS yang sulit dirubah karena kurangnya kesadaran masyarakat akan pentingnya kesehatan sanitasi menjadi penghambat utama. Meskipun telah berhasil memperbaiki peringkat akses jamban sehat, masih ditemukan banyak kendala saat pelaksanaan program ini. Untuk membantu percepatan pencapaian target sekaligus memberdayakan masyarakat di bidang ekonomi, Pemerintah membentuk Paguyuban Wirausaha Sanitasi.

Dalam penulisan ini, sebagai penutup penulis ingin memberikan saran 
kepada Dinas Kesehatan Kabupaten Tegal selaku leading sector. Untuk memaksimalkan implementasi program, perlu adanya monitoring dan evaluasi pasca pembangunan jamban secara simultan dan berkelanjutan. Prestasi pencapaian ODF tidak lepas dari komposisi peran komunikasi pemberdayaan yang dilakukan oleh para sanitarian. Perlu ditekankan peran penting komunikasi dalam pelaksanaan pemicuan. Komunikasi yang intensif, aktif dan efektif kepada masyarakat agar dapat berhasil merubah perilaku BABS masyarakat. Fasilitator harus lebih merangkul masyarakat dalam rangka menyadarkan mereka tentang akibat-akibat yang muncul dari buruknya sanitasi. Tidak seperti penyuluhan dan pelatihan pada umumnya, para fasilitator lebih banyak duduk bersama masyarakat dan menyelenggarakan diskusi serta mengadakan simulasi-simulasi yang menarik tentang perbaikan kualitas sanitasi. Hal tersebut tentu akan menyentuh jiwa dan harga diri masyarakat untuk meninggalkan keadaan keterbelekangan. Sehingga menghasilkan komitmen yang kuat untuk segera mengubah perilaku BABS. Saran bagi pemerintah desa, segera melaporkan data terbaru kaitannya dengan kemutakhiran PBDT dan segera membuat peraturan desa terkait penerapan Stop BABS.

\section{DAFTAR PUSTAKA}

Achmadi, Umar Fahmi. 2008. Horison Baru, Kesehatan Masyarakat Di Indonesia. Jakarta : Rineka Cipta

Adi, Isbandi Rukminto. 2007. Perencaan Partisiparotis Berbasis Aset Komunitas: dari Pemikiran Menuju Penerapan. Depok : FISIP UI Press

Arifianty, Della Putri. 2017. "Peran Pemerintah Lokal Dalam Peningkatan Sanitasi Lingkungan Masyarakat : Studi Tentang Keberhasilan Program Open Defecation Free (ODF) Di Kabupaten Bojonegoro”. Jurnal Kebijakan dan Manajemen Publik. Volume 5, Nomor 3. Universitas Airlangga

Davik, Farouk Ilmid. 2016. "Evaluasi Program Sanitasi Total Berbasis Masyarakat Pilar Stop BABS di Puskesmas Kabupaten Probolinggo”.Jurnal Administrasi Kesehatan Indonesia. Vol 4. Universitas Airlangga

Direktorat Jenderal Kesehatan Masyarakat. 2017. Panduan Praktis 5 Pilar STBM Untuk Masyarakat. Jakarta : Kementerian Kesehatan RI

Ditjen Pengendalian Penyakit dan Penyehatan Lingkungan. 2011. Modul Pelatihan Stop Buang Air Besar Sembarang (Stop BABS). Jakarta : Kementerian Kesehatan RI

Ditjen Pemberantasan Penyakit dan Penyehatan Lingkungan. 2015. Panduan Pelaksanaan Verifikasi 5 Pilar STBM. Jakarta : Kementerian Kesehatan RI

Istiyanto, S. Bekti. 2017. Komunikasi Pemberdayaan Masyarakat. Yogyakarta : Pustaka Ilmu

Kriyantono, Rachmat.2006. Teknik Praktis Riset Komunikasi. Jakarta: Kencana

Kriyantono, Rachmat. (2012). "Teknik Praktis Riset Komunikasi Cetakan ke-6”. Jakarta: Kencana Prenada Media Group. 
Moleong, Lexy J. 2004. Metodologi Penelitian Kualitatif. Bandung: PT. Remaja Rosdakarya

Moleong, Lexy J. 2006. Metodologi Penelitian Kualitatif. Bandung: PT. RemajaRosdakarya.

Notoatmodjo, Soekidjo. (2005). Promosi Kesehatan : Teori dan Aplikasi. Jakarta : PT. Rineka Cipta.

Peraturan Menteri Kesehatan No. 3 Tahun 2014 tentang Sanitasi Total Berbasis Masyarakat (STBM).

Peraturan Bupati Tegal Nomor 2 TAHUN 2018 tentang Juklak Program Daerah Pemberdayaan Masyarakat (PDPM)

Profil Kesehatan Kabupaten Tegal Tahun 2015. Pemerintah Daerah Kabupaten Tegal Dinas Kesehatan. 2016

Sholikhah, Siti. 2014. "Hubungan Pelaksanaan Program ODF (Open Defecation Free) dengan Perubahan Perilaku Masyarakat dalam Buang Air Besar di Luar Jamban di Desa Kemiri Kecamatan Malo Kabupaten Bojonegoro Tahun 2012”. Jurnal Surya. Vol 02. Stikes Muhammadiyah Lamongan

Sugiyono. 2013. Metode Penelitian Pendidikan Pendekatan Kuantitatif, Kualitatif, dan $R \& D$. Bandung: Alfabeta. 